Research article Open Access

\title{
Masitinib in the treatment of active rheumatoid arthritis: results of a multicentre, open-label, dose-ranging, phase 2 a study
}

\author{
Jacques Tebib1, Xavier Mariette², Pierre Bourgeois ${ }^{3}$, René-Marc Flipo ${ }^{4}$, Philippe Gaudin ${ }^{5}$, Xavier Le \\ Loët6, Paul Gineste7, Laurent Guy7, Colin D Mansfield7, Alain Moussy7, Patrice Dubreuil7,8,9, \\ Olivier Hermine 7,10 and Jean Sibilia ${ }^{11}$
}

\author{
1Service de Rhumatologie, Centre Hospitalier Lyon-Sud, 765 chemin du Grand-Revoyet, 69495 Pierre-Bénite, France \\ ${ }^{2}$ Service de Rhumatologie, Hôpital Bicêtre, Assistance Publique-Hôpitaux de Paris, 78 rue du Général Leclerc, 94275 Le Kremlin-Bicêtre Cedex, \\ France \\ ${ }^{3}$ Service de Rhumatologie, Groupe Hospitalier Pitié Salpétrière, 83 bd de l'Hôpital, 75013 Paris, France \\ ${ }^{4}$ Service de Rhumatologie, Hôpital Roger Salengro, Rue du Professeur Emile Laine, 59037 Lille cedex, France \\ ${ }^{5}$ Service de Rhumatologie, CHU Hôpital Sud - GREPI-TIMC-IMAG UMR CNRS 5525, Avenue de Kimberley, 38434 Échirolles, France \\ 6Service de Rhumatologie, CHU Hôpitaux de Rouen, 1 rue de Germont, 76230 Rouen, France \\ ${ }^{7}$ AB Science, S.A., 3 avenue Georges V, 75008 Paris, France \\ 8 Inserm U891, Centre de Recherche en Cancérologie de Marseille, Molecular and Functional Hematopoiesis, Centre de référence des mastocytoses, \\ 27 Bd Leï roure, 13009 Marseille, France \\ 9Institut Paoli-Calmettes, Marseille, France; Université Méditerranée, 27 Bd Leï roure, 13009 Marseille, France \\ ${ }^{10}$ CNRS UMR 8147, Service d'hématologie et centre de référence des mastocytoses, Hôpital Necker, 149 Rue de Sèvres, 75743 Paris, France \\ ${ }^{11}$ Service de Rhumatologie, Hôpital de Hautepierre, Avenue Molière - BP 49 - 67098 Strasbourg, France
}

Corresponding author: Jacques Tebib, jacques.tebib@chu-lyon.fr Olivier Hermine, ohermine@gmail.com

Received: 17 Feb 2009 Revisions requested: 9 Mar 2009 Revisions received: 5 May 2009 Accepted: 23 Jun 2009 Published: 23 Jun 2009

Arthritis Research \& Therapy 2009, 11:R95 (doi:10.1186/ar2740)

This article is online at: http://arthritis-research.com/content/11/3/R95

(c) 2009 Tebib et al.; licensee BioMed Central Ltd.

This is an open access article distributed under the terms of the Creative Commons Attribution License (http://creativecommons.org/licenses/by/2.0), which permits unrestricted use, distribution, and reproduction in any medium, provided the original work is properly cited.

\begin{abstract}
Introduction Since current treatment options for patients suffering from active rheumatoid arthritis (RA) remain inadequate, especially for those unresponsive to diseasemodifying antirheumatic drugs (DMARDs), new and improved medication is needed. This study evaluates the safety and efficacy of masitinib (AB1010), a potent and selective protein tyrosine kinase inhibitor of $\mathrm{c}-\mathrm{KIT}$, in the monotherapy treatment of DMARD-refractory RA.
\end{abstract}

Methods This was a multicentre, uncontrolled, open-label, randomised, dose-ranging, phase $2 a$ trial. Masitinib was administered orally to 43 patients who had inadequate response to DMARDs, at initial randomised dosing levels of 3 and $6 \mathrm{mg} /$ $\mathrm{kg}$ per day over a 12-week period. Dose adjustment was permitted based upon tolerability and response criteria. Efficacy was assessed via American College of Rheumatology 20\%/ $50 \% / 70 \%$ improvement criteria (ACR20/50/70) responses, disease activity score using 28 joint counts (DAS28), index of improvement in RA (ACRn) and C-reactive protein (CRP) improvement, relative to baseline at week 12 .
Results Improvement was observed in all efficacy endpoints, including ACR20/50/70 scores of $54 \%, 26 \%$ and $8 \%$, respectively, and a reduction in CRP level by greater than $50 \%$ for approximately half the population. This improvement was sustainable throughout an extension phase ( $>84$ weeks) and was also independent of initial DMARD resistance (anti-tumour necrosis factor-alpha and/or methotrexate). A relatively high patient withdrawal rate $(37 \%)$ required the use of last observation carried forward (LOCF) data imputation. Incidence of adverse events was high (95\%), although the majority were of mild or moderate severity with a considerable decline in frequency observed after 12 weeks of treatment. Two nonfatal serious adverse events were reported. Dose-response analyses tentatively indicate that an initial dosing level of $6.0 \mathrm{mg} / \mathrm{kg}$ per day administered orally in two daily intakes is the most appropriate, based upon potency and tolerability trends.

Conclusions Treatment with masitinib improved DMARDrefractory active RA. Following an initial high incidence of mostly mild to moderate side effects during the first 12 weeks of treatment, masitinib appears to be generally well tolerated. This,

ABL: Abelson kinase; ACR: American College of Rheumatology; ACR20/50/70/90: American College of Rheumatology 20\%/50\%/70\%/90\% improvement criteria; ACRn: index of improvement in rheumatoid arthritis; AE: adverse event; anti-TNF $\alpha$ : anti-tumour necrosis factor-alpha; CRP: Creactive protein; DAS28: disease activity score using 28 joint counts; DMARD: disease-modifying antirheumatic drug; IC $_{50}$ : half inhibitory concentration; IL1: interleukin-1; IL1-Ra: (recombinant) interleukin-1 receptor antagonist; ITT: intention-to-treat; LOCF: last observation carried forward; MC: mast cell; MTX: methotrexate; NSAID: nonsteroidal anti-inflammatory drug; OC: observed case; PDGFR: platelet-derived growth factor receptor; PP: per protocol; RA: rheumatoid arthritis; SAE: serious adverse event; SCF: stem cell factor; TK: tyrosine kinase. 
together with evidence of a sustainable efficacy response, suggests that masitinib is suitable for long-term treatment regimens. Since this was the first study of masitinib in a nononcologic pathology, the relatively high patient withdrawal rate observed can be partly attributed to a highly cautious response to adverse events. There is sufficient compelling evidence to warrant further placebo-controlled investigation. Trial registration ClinicalTrials.gov NCT00831922.

\section{Introduction}

Rheumatoid arthritis (RA) has a complex aetiopathogenesis necessitating that a patient's treatment be individually and continually tailored for effective management. Disease-modifying antirheumatic drugs (DMARDs), especially methotrexate (MTX), have become the cornerstone of RA treatment. A shortcoming of MTX, however, is that it is relatively ineffective at inducing remission, with disease progression continuing unabated in many patients $[1,2]$. A problem more general to DMARDs is that of drug resistance, which represents a major obstacle to the effective long-term management of RA [3]. Both MTX [4] and anti-tumour necrosis factor-alpha (anti$\mathrm{TNF} \alpha$ ) [5] may become inefficient for controlling disease activity in severe RA. Thus, beyond the already developed biological strategies, there exists an imperative need to identify alternative RA treatments that demonstrate high efficacy over time in monotherapy, exploit novel therapeutic targets for more effective combination therapies, minimise toxicity and are affordable. One such approach involves blocking intracellular proinflammatory messages, which is currently represented by the strategy of selective protein tyrosine kinase (TK) inhibition.

There is a growing body of evidence implicating mast cells (MCs) as major contributors to the pathogenesis of RA. MCs may be considered the immunological sentinel of the synovium, acting immediately in the event of joint trauma by liberating an array of proinflammatory mediators. However, MCs also appear to perpetuate the chronic process by their marked increased accumulation in the synovial lining of the inflamed joint and their ability to produce numerous proinflammatory cytokines and growth and angiogenic factors. Some of the most compelling evidence for the connection of MCs to RA comes from studies in the $\mathrm{K} / \mathrm{BxN}$ murine model, an animal model of autoantibody-induced arthritis, which has demonstrated that MC-deficient mice are resistant to arthritis, with susceptibility restored following MC engraftment [6]. This model has also been used to show how MCs contribute to the initiation of joint inflammation by elaboration of interleukin-1 (IL1) [7]. As such, MCs represent an attractive therapeutic target [8-13]. Stem cell factor (SCF), the ligand of the c-KIT receptor, is a critical growth factor for MCs and is essential to their survival, proliferation, differentiation, adhesion and degranulation processes [14]. Thus, there exists a strong relation between the SCF/MC c-KIT pathway and the pathogenesis of RA. It is hypothesised that, if this link were disrupted through the inhibitory action of c-KIT TK activity, then inflammatory diseases such as RA could be controlled; that is, MCs are strongly implicated in RA pathogenesis, SCF is closely associated with MCs, and c-KIT is intrinsically linked with SCF; hence, inhibition of the c-KIT pathway affects RA. Small molecules capable of blocking ATP binding and TK activity of c-KIT, both selectively and with a good safety profile, could therefore represent a new class of drugs effective in RA.

Masitinib (AB1010), the investigatory drug of this study, is a good candidate, being an ATP-binding site competitor that acts potently and selectively by inhibiting wild-type forms of c$\mathrm{KIT}$. In vitro masitinib has shown greater affinity and selectivity for human and murine c-KIT receptor (wild-type: half inhibitory concentration $\left[\mathrm{IC}_{50}\right]$ of $150 \mathrm{nM}$; juxtamembrane mutation: $\mathrm{IC}_{50}$ of $5 \mathrm{nM}$; P Dubreuil, S Letard, MA Ciufolini, L Gros, PS Leventhal, M Humbert, N Castéran, L Borge, B Hajem, A Lermet, W Sippl, E Voisset, M Arock, C Auclair, PS Leventhal, CD Mansfield, A Moussy \& O Hermine, manuscript submitted) as compared with imatinib mesylate (Gleevec, STI571; Novartis, Basel, Switzerland), the forerunner of such therapeutic agents. Masitinib also potently inhibits platelet-derived growth factor receptor-alpha (PDGFR $\alpha$ ), PDGFR $\beta$, Lyn and (to a lesser extent) fibroblast growth factor receptor 3 (FGFR3) and the focal adhesion kinase (FAK) activation pathway without inhibiting kinases of known toxicities (P. Dubreuil and colleagues, manuscript submitted). The maximal tolerated dose of masitinib has not been reached thus far in phase 1 studies of healthy volunteers or in cancer patients who were orally administered up to $1,000 \mathrm{mg} /$ day (corresponding to a weightadjusted dose of not more than $20 \mathrm{mg} / \mathrm{kg}$ per day for patients weighing at least $50 \mathrm{~kg}$; JC Soria, C Massard, N Magné, CD Mansfield, T Bader, A Moussy, O Hermine \& JP Armand, manuscript in preparation). However, it was observed that doses of higher than $12 \mathrm{mg} / \mathrm{kg}$ per day lead to gastrointestinal disorders that are probably not compatible with a long-term administration of masitinib. Dose levels of $7.5 \mathrm{mg} / \mathrm{kg}$ per day have shown no significant toxicity, with plasmatic concentrations of masitinib base detected at levels above the $\mathrm{IC}_{50}$ for C-KIT and PDGFR (J.C. Soria and colleagues, manuscript in preparation). The purpose of this current study was to evaluate the safety and efficacy of masitinib in the treatment of DMARDrefractory active $\mathrm{RA}$.

\section{Materials and methods Patients}

Patients from 18 to 75 years of age who had been diagnosed with active RA, according to the American College of Rheumatology (ACR) criteria [15], for whom disease onset had occurred after 16 years of age and who had a history of DMARD failure (predominantly MTX and/or anti-TNF $\alpha$ ) or pri- 
mary resistance to anti-TNF $\alpha$ were eligible to participate. Their active RA had an ACR functional class of 1 to 3 [16] and a duration of at least 6 months. In addition, patients exhibited at least $8 / 66$ swollen joints, at least $10 / 68$ painful joints and at least one of the following three conditions: erythrocyte sedimentation rate of at least $28 \mathrm{~mm} /$ hour, C-reactive protein (CRP) of at least $15 \mathrm{mg} /$ litre or morning stiffness for at least 45 minutes at both screening and baseline time points. The main exclusion criteria were patients with inadequate bone marrow function (defined as an absolute neutrophil count of not more than $2.5 \times 10^{9} /$ litre) and a platelet count of not more than $100 \times 10 \% /$ litre, active current infection, history of infection requiring hospitalisation, history of recurrent infections or treatment with antibiotics within 2 weeks of screening. Treatment washout or exclusion periods observed prior to entry to the study were (a) DMARD use within 4 weeks, (b) five halflives or washout in accordance with a specific drug (whichever is longer) (c) any live (attenuated) vaccines taken within 4 weeks, (d) use of more than one nonsteroidal anti-inflammatory drug (NSAID) or change of its dosage within 4 weeks, (e) dosage of prednisone or equivalent corticosteroid of greater than $10 \mathrm{mg} /$ day or any dosage change within 4 weeks, and (f) dosage of prednisone or equivalent corticosteroid of greater than $20 \mathrm{mg}$ administered via intra-articular injection or bolus intramuscular or intravenous treatment within 4 weeks. Other exclusion criteria included any previous use of recombinant IL1 receptor antagonist (IL1-Ra) and patients who were pregnant or nursing.

\section{Study design and drug product}

This was a multicentre, prospective, uncontrolled, open-label, randomised, dose-ranging, phase 2a study of masitinib in adults with active RA, who were followed over the course of a 12-week period. The study was approved by the local ethics committees and was carried out in compliance with the Declaration of Helsinki and good clinical practices guidelines. Written informed consent was obtained from all patients. The study was registered in ClinicalTrials.gov under the trial registration number NCT00831922.

Masitinib, supplied as 100 and $200 \mathrm{mg}$ tablets (AB Science, Paris, France), was administered orally in two daily intakes. To evaluate the dose response of masitinib in DMARD-refractory active RA, dose ranging was performed by randomly assigning patients to one of two initial treatment groups of 3 and $6 \mathrm{mg} /$ $\mathrm{kg}$ per day (1:1 ratio). Dosage could be increased by $1.5 \mathrm{mg} /$ $\mathrm{kg}$ per day at weeks 4 and 8 in the event of insufficient response accompanied by minimal toxicity. Likewise, the dose could be reduced by $1.5 \mathrm{mg} / \mathrm{kg}$ per day or treatment discontinued in case of serious adverse events (SAEs). Patients exhibiting a significant improvement after 12 weeks of treatment were eligible to continue receiving treatment after entering a compassionate program, wherein assessments were performed every 4 weeks for the first 3 months of extension and every 12 weeks thereafter.
Permitted medications for the treatment of possible cutaneous rash and face oedema during the study were hydroxyzine (Atarax) and prednisolone. Other permitted concomitant medications were one NSAID (including cyclooxygenase 2 [COX2] inhibitors) at constant dosage, oral corticosteroids at stable doses of not more than $10 \mathrm{mg} /$ day, analgesics without antiinflammatory action or oral narcotic analgesics and medically acceptable forms of birth control. Physical therapy, if performed at the time of study entry, was provided under a stable and consistent regimen. The following treatments of active RA were prohibited during the study: surgery, DMARD treatment (including MTX, anti-TNF $\alpha$ biology therapies, leflunomide, IL1$\mathrm{Ra}$, azathioprine and cyclosporine), immunosuppressive drugs, cytotoxic drugs, intramuscular or intravenous injections of steroids, intra-articular or soft tissue injections of corticosteroids and alternate investigational drugs or investigational combinations of approved drugs. Drugs that interact with the same CYP450 isoenzymes (2C9, 2D6 and 3A4) as masitinib were prohibited (for example, acetaminophen) due to the inherent risk of either reduced activity or enhanced toxicity of any concomitant medication. Finally, the use of analgesics was prohibited on assessment days until after all clinical efficacy evaluations had been completed.

\section{Safety and efficacy assessment}

Safety was assessed by occurrence of adverse events (AEs) and SAEs and monitoring biochemical, haematological and urinalysis parameters during the study period, with toxicity graded according to the Common Toxicity Criteria version 3.0. In the event of SAE (that is, grade 3 or 4), treatment was interrupted until resolution and then resumed, with a permitted dose reduction of $1.5 \mathrm{mg} / \mathrm{kg}$ per day or treatment discontinuation if toxicity recurred. Evaluation of treatment efficacy was based upon the evolution of clinical symptoms associated with active RA at week 12 relative to baseline. Primary endpoints were the ACR response criteria of ACR20, ACR50 and ACR70 [17]. For each patient, all efficacy parameters were recorded on the first day of treatment (baseline), prior to administration of masitinib and then again after 4,8 and 12 weeks of treatment. Secondary endpoints included the 12week analysis of disease activity score using 28 joint counts (DAS28) [18], index of improvement in RA (ACRn) [19] and CRP improvement. Higher DAS28 values are indicative of greater disease activity with significance placed on the threshold values of DAS28 $<2.6,2.6 \leq$ DAS2 $2 \leq 3.2,3.2<$ DAS28 $\leq 5.1$, and DAS28 $>5.1$, corresponding to the classifications of remission, inactive RA, moderate RA and very active RA, respectively. CRP is an acute-phase reactant and a sensitive serum marker of inflammation. Discrimination between dose regimens was investigated by analysis of the time (days) to first ACR variable response according to initial dosage. Since dose adjustment was permitted at weeks 4 and 8 in cases of insufficient treatment response, the dose at the time of first response was also analysed. 


\section{Statistical methods}

Efficacy data are presented using descriptive statistics, contrasting initial dosage groups or according to previous DMARD failure. For comparison of groups according to initial dosage on a continuous variable, the Student test (with Satterwhaite correction for unequal variance) or the Wilcoxon test was used when normality was not rejected or was rejected, respectively (normality determined via the Shapiro-Wilk test). For the same comparison on a qualitative variable, the chisquare or Fisher exact test (if the chi-square hypotheses were not fulfilled) was used. The rates of patients achieving the various ACR response variables after 12 weeks of treatment (remission rate) are presented in terms of number and percentage of patients. Patients were assigned to either 3 or $6 \mathrm{mg} / \mathrm{kg}$ per day treatment groups based upon a randomisation schedule generated for packaging and labelling by the Biostatistics Section of $A B$ Science. Individual treatment doses to be administered were supplied in sealed envelopes to be opened by the investigator at the time of inclusion. Patients received the treatment from the investigator on an open basis.

Due to the relatively high patient dropout rate of this study, analysis was conducted on two different datasets: one with an imputation of missing values according to the last observation carried forward (LOCF) methodology and the other in the absence of data imputation (that is, the observed cases [OCs]). Analysis for efficacy was performed on a modified intention-to-treat (ITT) population and per protocol (PP) population. The ITT population was defined as those patients who had received at least one dose of masitinib and who had undergone at least one post-baseline assessment of efficacy. The PP population was defined as a subgroup of the ITT population that in addition had presented no major protocol deviations and had completed at least 28 days of treatment exposure.

\section{Results}

\section{Baseline characteristics and participant flow}

Between December 2004 and March 2006, a total of 43 patients were enrolled in the study. Participants were randomly assigned to one of two initial treatment groups, receiving a masitinib dosage of either $3 \mathrm{mg} / \mathrm{kg}$ per day $(\mathrm{n}=22)$ or 6 $\mathrm{mg} / \mathrm{kg}$ per day $(\mathrm{n}=21)$. Of these, $27 / 43(63 \%)$ patients completed the study, with $21 / 43(49 \%)$ patients entering the study's extension phase (10/43 [23\%] patients received treatment for more than 1 year, $8 / 43$ [19\%] for more than 2 years and $3 / 43$ [7\%] for more than 3 years). Of the $16(37 \%)$ patients who withdrew before completion of the 12-week study period, occurrence of an AE was cited as the primary cause of discontinuation. Participant baseline characteristics, disposition and dosing history are presented in Table 1 according to the randomised dose-ranging treatment groups. Baseline values of several efficacy parameters were higher in the $6 \mathrm{mg} / \mathrm{kg}$ per day group compared with the $3 \mathrm{mg} / \mathrm{kg}$ per day group; for example, DAS28 was, respectively, 7.1 versus 6.1
( $P=0.010), \mathrm{CRP}$ was 62 versus $26 \mathrm{mg} /$ litre $(P=0.029)$, swollen joint count was 22.1 versus $15.3(P=0.046)$, previous anti-TNF $\alpha$ was $67 \%$ versus $36 \%(P=0.056)$ and Health Assessment Questionnaire score was 2.2 versus $1.9(P=$ 0.082 ). Hence, the $6 \mathrm{mg} / \mathrm{kg}$ per day initial dosage arm had a higher baseline of disease severity.

Three patients were excluded from the randomised population due to lack of efficacy data following baseline; thus, according to our ITT population definition, the resulting ITT population was $n=40$. This corresponded to 3 and $6 \mathrm{mg} / \mathrm{kg}$ per day randomised dose-ranging groups of $n=22$ and $n=18$, respectively. Four other patients were excluded from the PP population ( $n=36$ with $n=18$ for each group): one due to a major protocol violation (that is, treated with prednisone at 20 $\mathrm{mg}$ /day before baseline) and three due to insufficient exposure time (that is, fewer than 28 days).

In regard to analysis of the primary efficacy outcome (that is, ACR score at week 12), 39/40 (97\%) patients had sufficient post-baseline data available for analysis in the ITT LOCF group. (The size of this efficacy analysis group differs from that of the ITT population since, although the missing patient fulfilled the ITT criteria, he did not possess a sufficiently complete dataset to permit calculation of the multiparametric ACR score.) The PP OC efficacy analysis group had sufficient data available for analysis of $27 / 36$ (75\%) patients. Secondary efficacy outcomes were likewise analysed according to the number of patients possessing sufficient data for evaluation at 12 weeks.

Subgroup analysis of the ITT population with respect to previous DMARD treatment failure revealed that 20/40 (50\%) patients were unresponsive to anti-TNF $\alpha$ (including $5 / 40$ [12\%] patients resistant to one anti-TNF $\alpha, 10 / 40$ [25\%] patients resistant to more than one anti-TNF $\alpha$ and 5/40 [12\%] patients intolerant to anti-TNF $\alpha$ ). In addition, 33/40 (82\%) patients were unresponsive to MTX. Among them, 18 patients were unresponsive to both anti-TNF $\alpha$ and MTX. Analyses of the participant baseline characteristics with respect to previous treatment failure (data not shown) suggest that, although the entire population was classified as having 'very active RA', those patients previously treated with anti-TNF $\alpha$ were suffering from RA of even greater severity than that of the other patients.

\section{Safety and tolerability of masitinib}

Assessment of safety was performed on all patients who had received at least one dose of masitinib $(n=43)$ over the study duration, including the treatment extension period with a cutoff date of 31 August 2008. Overall patient exposure to masitinib was $288 \pm 378$ days on average, with a median exposure of 91 days and a range of 8 to 1,274 days. The incidence of common $(>4 \%)$ treatment-related AEs according to intensity is presented in Table 2 for the initial (12-week study period) and 
Table 1

\section{Baseline characteristics, overall disposition and dosing history, according to initial dosage}

\begin{tabular}{|c|c|c|c|}
\hline Parameter & $\begin{array}{c}\text { Masitinib } 3 \mathrm{mg} / \mathrm{kg} \text { per day } \\
\qquad(\mathrm{n}=22)\end{array}$ & $\begin{array}{c}\text { Masitinib } 6 \mathrm{mg} / \mathrm{kg} \text { per day } \\
(\mathrm{n}=18)\end{array}$ & $\begin{array}{l}\text { Total population } \\
(n=40)\end{array}$ \\
\hline \multicolumn{4}{|l|}{ Demographic (intent-to-treat population) } \\
\hline \multicolumn{4}{|l|}{ Age, years } \\
\hline Mean \pm SD & $54.0 \pm 12.2$ & $55.5 \pm 9.2$ & $54.7 \pm 10.8$ \\
\hline Range & $27.0-75.0$ & $34.0-69.0$ & $27.0-75.0$ \\
\hline \multicolumn{4}{|l|}{ Weight, kg } \\
\hline Mean \pm SD & $67.1 \pm 12.8$ & $69.2 \pm 20.5$ & $68.1 \pm 16.5$ \\
\hline Range & $49.0-88.0$ & $50.0-136.0$ & $49.0-136.0$ \\
\hline \multicolumn{4}{|l|}{ Gender } \\
\hline Male & $3 / 22(13.6 \%)$ & 6/18 (33.3\%) & $9 / 40(22.5 \%)$ \\
\hline Female & $19 / 22(86.4 \%)$ & $12 / 18(66.7 \%)$ & $31 / 40(77.5 \%)$ \\
\hline \multicolumn{4}{|l|}{ Clinical (intent-to-treat population) } \\
\hline Disease duration in years, mean $\pm S D$ & $11.8 \pm 5.9$ & $10.7 \pm 8.1$ & $11.3 \pm 6.9$ \\
\hline Tender joints, mean \pm SD & $24.7 \pm 11.1$ & $32.2 \pm 16.3$ & $28.1 \pm 14.0$ \\
\hline Swollen joints, mean \pm SD & $15.3 \pm 10.4$ & $22.1 \pm 12.0$ & $18.4 \pm 11.5$ \\
\hline Patient pain assessment, mean \pm SD & $67.4 \pm 19.2$ & $68.6 \pm 27.4$ & $67.9 \pm 23.0$ \\
\hline Patient assessment of $D A$, mean $\pm S D$ & $69.4 \pm 24.9$ & $73.0 \pm 22.9$ & $71.0 \pm 23.8$ \\
\hline Physician assessment of $\mathrm{DA}$, mean $\pm \mathrm{SD}$ & $66.4 \pm 19.5$ & $66.8 \pm 18.8$ & $66.6 \pm 18.9$ \\
\hline $\mathrm{HAQ}$ score, mean $\pm \mathrm{SD}$ & $1.9 \pm 0.6$ & $2.2 \pm 0.5$ & $2.0 \pm 0.6$ \\
\hline $\mathrm{CRP}$ (mg/litre), mean $\pm \mathrm{SD}$ & $26.2 \pm 28.4$ & $62.3 \pm 57.6$ & $42.3 \pm 46.9$ \\
\hline DAS28, mean \pm SD & $6.1 \pm 0.8$ & $7.1 \pm 1.1$ & $6.5 \pm 1.0$ \\
\hline \multicolumn{4}{|l|}{ DMARD failures (percentage) } \\
\hline Anti-TNF $\alpha$ & $8 / 22(36.4 \%)$ & $12 / 18(66.7 \%)$ & $20 / 40(50.0 \%)$ \\
\hline Other & $14 / 22(63.6 \%)$ & $6 / 18(33.3 \%)$ & $20 / 40(50.0 \%)$ \\
\hline \multicolumn{4}{|l|}{ Patient disposition (randomised population) } \\
\hline & $\begin{array}{l}\text { Masitinib } 3 \mathrm{mg} / \mathrm{kg} \text { per day } \\
\qquad(\mathrm{n}=22)\end{array}$ & $\begin{array}{l}\text { Masitinib } 6 \mathrm{mg} / \mathrm{kg} \text { per day } \\
\qquad(\mathrm{n}=21)\end{array}$ & $\begin{array}{l}\text { Total population } \\
\quad(n=43)\end{array}$ \\
\hline Early study discontinuation & $7 / 22(31.8 \%)$ & $9 / 21(42.9 \%)$ & $16 / 43(37.2 \%)$ \\
\hline Insufficient therapeutic effect & $1 / 7(14.3 \%)$ & $1 / 9(11.1 \%)$ & $2 / 16(12.5 \%)$ \\
\hline Protocol violation & $0 / 7(0.0 \%)$ & $0 / 9(0.0 \%)$ & $0 / 16(0.0 \%)$ \\
\hline Adverse event & $6 / 7(85.7 \%)$ & $7 / 9(77.8 \%)$ & $13 / 16(81.3 \%)$ \\
\hline Consent withdrawn & $0 / 7(0.0 \%)$ & $1 / 9(11.1 \%)$ & $1 / 16(6.3 \%)$ \\
\hline End of study without extension & $5 / 22(22.7 \%)$ & $1 / 21(4.8 \%)$ & $6 / 43(14.0 \%)$ \\
\hline Entered extension phase & $10 / 22(45.4 \%)$ & $11 / 21(52.3 \%)$ & $21 / 43(48.9 \%)$ \\
\hline \multicolumn{4}{|c|}{ Dosing adjustment (intent-to-treat population over 12-week study phase) } \\
\hline & $\begin{array}{l}\text { Masitinib } 3 \mathrm{mg} / \mathrm{kg} \text { per day } \\
\qquad(\mathrm{n}=22)\end{array}$ & $\begin{array}{c}\text { Masitinib } 6 \mathrm{mg} / \mathrm{kg} \text { per day } \\
(\mathrm{n}=18)\end{array}$ & $\begin{array}{l}\text { Total population } \\
\quad(n=40)\end{array}$ \\
\hline No dose adjustment & $10 / 22(45 \%)$ & $8 / 18(44 \%)$ & $18 / 40(45 \%)$ \\
\hline Increase by $1.5 \mathrm{mg} / \mathrm{kg}$ per day & $6 / 22(27 \%)$ & $3 / 18(17 \%)$ & $9 / 40(23 \%)$ \\
\hline Increase by $3.0 \mathrm{mg} / \mathrm{kg}$ per day & $2 / 22(9 \%)$ & $5 / 18(28 \%)$ & $7 / 40(18 \%)$ \\
\hline Increase by $4.5 \mathrm{mg} / \mathrm{kg}$ per day & $3 / 22(14 \%)$ & $0 / 18(0 \%)$ & $3 / 40(8 \%)$ \\
\hline Othera & $1 / 22(5 \%)$ & $2 / 18(11 \%)$ & $3 / 40(8 \%)$ \\
\hline
\end{tabular}

Active rheumatoid arthritis patients were randomly assigned to receive masitinib therapy at initial dosing levels of 3.0 or $6.0 \mathrm{mg} / \mathrm{kg}$ per day, administered per os for 12 weeks. Dose adjustment was permitted depending upon efficacy and safety assessments. Pain and disease activity were assessed using an EQ-5D (EuroOoL-5 Dimensions) visual analogue scale. aCombination of dose augmentation and/or diminution. AntiTNF $\alpha$, anti-tumour necrosis factor-alpha; CRP, C-reactive protein; DA, disease activity; DAS28, disease activity score using 28 joint counts; DMARD, disease-modifying antirheumatic drug; HAQ, Health Assessment Questionnaire; SD, standard deviation. 
Table 2

Number (percentage) of subjects with at least one suspected (or not assessable) adverse event, according to intensity

\begin{tabular}{|c|c|c|c|c|}
\hline \multicolumn{5}{|c|}{ Initial phase } \\
\hline System organ class/preferred terma & All $(n=43)$ & Mild & Moderate & Severe \\
\hline At least one suspected $A E^{b}$ & $40(93.0 \%)$ & $29(67.4 \%)$ & $27(62.8 \%)$ & $9(20.9 \%)$ \\
\hline Rash-All categories & $13(30.2 \%)$ & $7(16.3 \%)$ & $8(18.6 \%)$ & $2(4.7 \%)$ \\
\hline Oedema-All categories & $11(25.6 \%)$ & $2(4.7 \%)$ & $6(14.0 \%)$ & $3(7.0 \%)$ \\
\hline Nausea & $10(23.3 \%)$ & $6(14.0 \%)$ & $5(11.6 \%)$ & \\
\hline Diarrhoea & $8(18.6 \%)$ & $5(11.6 \%)$ & $2(4.7 \%)$ & $1(2.3 \%)$ \\
\hline Headache & $6(14.0 \%)$ & $4(9.3 \%)$ & $2(4.7 \%)$ & \\
\hline Abdominal pain, upper & $5(11.6 \%)$ & $4(9.3 \%)$ & $1(2.3 \%)$ & \\
\hline Vomiting & $5(11.6 \%)$ & $1(2.3 \%)$ & $4(9.3 \%)$ & \\
\hline Asthenia & $5(11.6 \%)$ & & $4(9.3 \%)$ & $1(2.3 \%)$ \\
\hline Pyrexia & $3(7.0 \%)$ & $1(2.3 \%)$ & $1(2.3 \%)$ & $1(2.3 \%)$ \\
\hline Herpes simplex & $3(7.0 \%)$ & $2(4.7 \%)$ & $1(2.3 \%)$ & \\
\hline Weight decreased & $3(7.0 \%)$ & $2(4.7 \%)$ & $1(2.3 \%)$ & \\
\hline Dyspnoea & $3(7.0 \%)$ & $1(2.3 \%)$ & $1(2.3 \%)$ & $1(2.3 \%)$ \\
\hline Abdominal pain & $2(4.7 \%)$ & $1(2.3 \%)$ & & $1(2.3 \%)$ \\
\hline Dry mouth & $2(4.7 \%)$ & $1(2.3 \%)$ & & $1(2.3 \%)$ \\
\hline Hyperthermia & $2(4.7 \%)$ & & $1(2.3 \%)$ & $1(2.3 \%)$ \\
\hline Gastroenteritis & $2(4.7 \%)$ & & $2(4.7 \%)$ & \\
\hline Blood creatinine increased & $2(4.7 \%)$ & $1(2.3 \%)$ & $1(2.3 \%)$ & \\
\hline Cough & $2(4.7 \%)$ & $1(2.3 \%)$ & $1(2.3 \%)$ & \\
\hline Alopecia & $2(4.7 \%)$ & $2(4.7 \%)$ & & \\
\hline Petechiae & $2(4.7 \%)$ & $1(2.3 \%)$ & $1(2.3 \%)$ & \\
\hline \multicolumn{5}{|c|}{ Extension phase } \\
\hline System organ class/preferred term & All $(n=21)$ & Mild & Moderate & Severe \\
\hline At least one suspected $A E$ & $10(47.6 \%)$ & $4(19.0 \%)$ & $3(14.3 \%)$ & $3(14.3 \%)$ \\
\hline Oedema-All categories & $2(9.5 \%)$ & & $2(9.5 \%)$ & \\
\hline Leukopenia & $1(4.8 \%)$ & & $1(4.8 \%)$ & \\
\hline Vertigo & $1(4.8 \%)$ & & $1(4.8 \%)$ & \\
\hline Aphthous stomatitis & $1(4.8 \%)$ & $1(4.8 \%)$ & & \\
\hline Asthenia & $1(4.8 \%)$ & $1(4.8 \%)$ & & \\
\hline Pyrexia & $1(4.8 \%)$ & $1(4.8 \%)$ & & \\
\hline Liver disorder & $1(4.8 \%)$ & & & $1(4.8 \%)$ \\
\hline Gastroenteritis & $1(4.8 \%)$ & $1(4.8 \%)$ & & \\
\hline Nasopharyngitis & $1(4.8 \%)$ & $1(4.8 \%)$ & & \\
\hline Rhinitis & $1(4.8 \%)$ & $1(4.8 \%)$ & & \\
\hline Neutrophil count decreased & $1(4.8 \%)$ & $1(4.8 \%)$ & & \\
\hline Rheumatoid arthritis & $1(4.8 \%)$ & & & $1(4.8 \%)$ \\
\hline Bronchopneumopathy & $1(4.8 \%)$ & & & $1(4.8 \%)$ \\
\hline Pleural effusion & $1(4.8 \%)$ & & & $1(4.8 \%)$ \\
\hline Eczema & $1(4.8 \%)$ & $1(4.8 \%)$ & & \\
\hline Onychoclasis & $1(4.8 \%)$ & $1(4.8 \%)$ & & \\
\hline Photosensitivity reaction & $1(4.8 \%)$ & $1(4.8 \%)$ & & \\
\hline
\end{tabular}

Table includes those adverse events (AEs) that occurred commonly (that is, in greater than $4 \%$ of patients). aMedDRA (medical dictionary for regulatory activities) terminology. ${ }^{\mathrm{b}} \mathrm{AE}$ intensity count is cumulative. AEs were recorded only once (at their start date). 
extension phases. A total of $40 / 43(93 \%)$ patients reported at least one masitinib-related (or not assessable) AE during the initial phase. In general, AEs were transient in nature and of mild to moderate intensity; nevertheless, occurrence of AEs was the main reason that $13 / 43(30 \%)$ patients discontinued treatment. In 9/43 (21\%) patients, the AEs were severe, including oedema and rash in $3 / 43(7 \%)$ and $2 / 43(5 \%)$ patients, respectively. One patient presented with angioedema of moderate intensity (face oedema, rash and dyspnea without hypotension or any sign of shock). This event resolved upon masitinib interruption and without specific medications, ruling out any anaphylactic or anaphylactic-like reaction. No changes considered to be of clinical relevance were observed in regard to physical, haematological or urinalysis parameters during the initial phase; however, 1/43 (2\%) patient presented with hepatic disorder of increased liver enzymes (aspartate amino transferase: 122 units/litre, alanine amino transferase: 188 units/litre and alkaline phosphatase: 635 units/litre) at a dose of $6 \mathrm{mg} / \mathrm{kg}$ per day. This episode, reported as a severe transaminase increase $\mathrm{AE}$, occurred after 14 days of treatment and resolved within 4 weeks of drug withdrawal, with no reoccurrence following the reintroduction of treatment. Analysis of AEs with respect to the dose of their occurrence (data not shown) showed that no clear dose-toxicity relationships exist, with the exception of oedema. The number of patients experiencing at least one oedema was $11 /$ $43(26 \%)$, with $6 / 36(16.7 \%)$ for doses of not more than 6.0 $\mathrm{mg} / \mathrm{kg}$ per day and $5 / 15$ (33.3\%) for doses of greater than 6.0 $\mathrm{mg} / \mathrm{kg}$ per day. Such oedematous episodes typically occurred 4 weeks (median onset time of 28 days) after the first drug intake or dose increase and abated within an average of 16 days. Four (9\%) patients reported nonfatal SAEs of severe intensity which were suspected to be related to masitinib (or not assessable) and which consisted of skin rash, pleural effusion, pneumonia and RA flare-up. Only one of those SAEs (pleural effusion) resulted in patient withdrawal. All of these patients recovered without sequelae, and no deaths occurred during this study.

For patients entering the extension phase $(n=21)$, a clear decrease in the occurrence of $A E s$ as well as a reduction in severity were evident. Overall, 10/21 (48\%) patients reported at least one masitinib-related (or not assessable) $\mathrm{AE}$; these AEs were of mild, moderate or severe intensity in $4 / 21$ (19\%), $3 / 21(14 \%)$ and $3 / 21(14 \%)$ patients, respectively. Specifically, no incidence of skin rash, nausea, vomiting or diarrhoea was reported after week 12, and occurrence of oedema decreased more than $60 \%$.

\section{Clinical efficacy of masitinib}

Evaluation of the primary efficacy endpoint ACR and the secondary endpoints of ACRn, DAS28 and CRP improvement is presented in Table 3 according to the ITT LOCF and PP OC analysis groups. Treatment with masitinib significantly improved the severity of active RA: at week 12, ACR20,
ACR50 and ACR70 were achieved by 15/27 (55.6\%), 9/27 (33.3\%) and $3 / 27$ (11.1\%) patients, respectively, in the PP OC group. The corresponding numbers in the ITT LOCF group were 21/39 (53.8\%), 10/39 (25.6\%) and 3/39 (7.7\%). These results are presented as the cumulative number of patients reaching each ACR level, with performance observed to be similar between efficacy analysis groups; the slightly lower response in ITT LOCF was attributable to the fact that imputed data were typically associated with patient withdrawal and, therefore, a lower treatment exposure. Considerable improvement was also observed in the ACRn analysis, the PP $\mathrm{OC}$ and ITT LOCF analysis groups achieving an improvement of 31.6 and 23.0 units, respectively, at week 12 . With respect to DAS28 values, the PP OC and ITT LOCF populations exhibited an absolute change of 2.0 and 1.7 units, respectively, from a baseline of 6.5 units, representing an improvement in DAS28 classification from 'very active RA' to 'moderate RA'. In regard to the number of patients with a DAS28 of less than 2.6 (classified as disease remission), two patients from the ITT LOCF population's MTX subgroup exhibited this improvement but none from the anti-TNF $\alpha$ subgroup did. Finally, approximately $50 \%$ of patients experienced a significant reduction $(>50 \%)$ in their CRP levels, signifying a decrease in their inflammation.

The pattern of masitinib efficacy appears to be independent of previous treatment failure, with approximately $50 \%$ of patients achieving the ARC20 and $\triangle \mathrm{CRP}$ greater than $50 \%$ response criteria regardless of previous treatment (Table 3 ); that is, masitinib is equally effective in patients for whom previous treatment with anti-TNF $\alpha$ or MTX has been inadequate. Preliminary results from the extension phase are of major interest since they show the observed improvement to be consistently maintained over a duration of more than 84 weeks, demonstrating masitinib's sustainability (Table 4). In regard to the DAS28 extension phase data after 1 year of treatment ( 60 weeks), an increasing number of patients were achieving DAS28 values of not more than 3.2 or less than 2.6, signifying inactive RA or an increased likelihood of being in remission. Furthermore, over this time, two patients achieved up to $90 \%$ improvement (ACR90). Taken together, this suggests that further therapeutic gains could possibly be achieved given longer exposure times.

\section{Dose analysis}

An analysis of time to first response according to initial dosage is presented in Table 5. This analysis extends to the extension phase for a total assessment period of approximately 32 weeks. Patients randomly assigned to the $6 \mathrm{mg} / \mathrm{kg}$ per day dosing group achieved a response faster than those assigned to the $3 \mathrm{mg} / \mathrm{kg}$ per day (ACR20: median of 29 versus 56 days $[P=0.231]$; ACR50: 72.5 versus 84 days $[P=0.771]$, respectively); however, these differences were not statistically significant $(P<0.05)$. In cases of insufficient treatment response, dose adjustment was permitted at weeks 4 and 8 ; 
Table 3

Summary of efficacy outcomes at week 12 with subgroup analysis according to previous treatment failure

\begin{tabular}{|c|c|c|c|c|c|c|}
\hline \multirow[t]{2}{*}{ Parameter } & \multicolumn{3}{|c|}{ PP OCs } & \multicolumn{3}{|c|}{ ITT LOCF } \\
\hline & All patients & $\begin{array}{l}\text { Resistance to } \\
\text { anti-TNF } \alpha\end{array}$ & Resistance to MTX & All patients & $\begin{array}{l}\text { Resistance to } \\
\text { anti-TNF } \alpha\end{array}$ & $\begin{array}{l}\text { Resistance to } \\
\text { MTX }\end{array}$ \\
\hline $\mathrm{ACR}^{\mathrm{a}}$ & $(n=27)$ & $(n=14)$ & $(n=23)$ & $(n=39)$ & $(n=19)$ & $(n=32)$ \\
\hline ACR20 & $15 / 27(55.6 \%)$ & $8 / 14(57.1 \%)$ & $14 / 23(60.9 \%)$ & 21/39 (53.8\%) & $10 / 19(52.6 \%)$ & 17/32 (53.1\%) \\
\hline ACR50 & 9/27 (33.3\%) & 4/14 (28.6\%) & 9/23 (39.1\%) & $10 / 39(25.6 \%)$ & $4 / 19(21.1 \%)$ & $9 / 32(28.1 \%)$ \\
\hline ACR70 & $3 / 27$ (11.1\%) & $1 / 14(7.1 \%)$ & $3 / 23(13.0 \%)$ & 3/39 (7.7\%) & $1 / 19$ (5.3\%) & $3 / 32$ (9.4\%) \\
\hline \multicolumn{7}{|l|}{ ACRn } \\
\hline Mean \pm SD & $31.6 \pm 33.5$ & $28.1 \pm 32.1$ & $36.6 \pm 31.6$ & $23.0 \pm 37.5$ & $18.7 \pm 36.8$ & $24.1 \pm 38.8$ \\
\hline Median & 42.9 & 44.3 & 46.9 & 25.7 & 20.6 & 32.7 \\
\hline Range & $-40.0-87.5$ & $-40.0-72.2$ & $-40.0-87.5$ & $-62.5-87.5$ & $-62.5-72.2$ & $-62.5-87.5$ \\
\hline CRP & $(n=28)$ & $(n=14)$ & $(n=23)$ & $(n=35)$ & $(n=17)$ & $(n=29)$ \\
\hline Improvement $>50 \%$ & $14 / 28(50.0 \%)$ & $7 / 14(50.0 \%)$ & $12 / 23(52.2 \%)$ & $19 / 35(54.3 \%)$ & $9 / 17$ (52.9\%) & $16 / 29(55.2 \%)$ \\
\hline $25 \%<$ improvement $\leq 50 \%$ & $3 / 28(10.7 \%)$ & $1 / 14(7.1 \%)$ & $2 / 23(8.7 \%)$ & 4/35 (11.4\%) & $2 / 17(11.8 \%)$ & $3 / 29(10.3 \%)$ \\
\hline $0 \% \leq$ improvement $\leq 25 \%$ & $5 / 28(17.9 \%)$ & $1 / 14(7.1 \%)$ & $3 / 23(13.0 \%)$ & $5 / 35(14.3 \%)$ & $1 / 17(5.9 \%)$ & $3 / 29(10.3 \%)$ \\
\hline Stability & $3 / 28(11 \%)$ & $3 / 14(21 \%)$ & $3 / 23(13 \%)$ & $3 / 35(9 \%)$ & $3 / 17(18 \%)$ & $3 / 29(10 \%)$ \\
\hline Deterioration & $3 / 28(11 \%)$ & $2 / 14(14 \%)$ & $3 / 23(13 \%)$ & $4 / 35(11 \%)$ & $2 / 17(12 \%)$ & $4 / 29(14 \%)$ \\
\hline DAS28 & $(n=24)$ & $(n=13)$ & $(n=20)$ & $(n=34)$ & $(n=18)$ & $(n=28)$ \\
\hline Mean \pm SD & $4.6 \pm 1.3$ & $5.1 \pm 1.2$ & $4.6 \pm 1.4$ & $4.8 \pm 1.5$ & $5.2 \pm 1.1$ & $4.8 \pm 1.5$ \\
\hline$\triangle \mathrm{DAS} 28$ & 2.0 & 1.8 & 2.1 & 1.7 & 1.7 & 1.8 \\
\hline Range & $0.5-7.0$ & $3.3-7.0$ & $0.5-7.0$ & $0.5-7.0$ & $3.3-7.0$ & $0.5-7.0$ \\
\hline DAS28 $<2.6$ & $1 / 24(4.2 \%)$ & $0 / 28(0 \%)$ & $1 / 20(5.0 \%)$ & 2/34 (5.9\%) & $0 / 18(0 \%)$ & $2 / 28(7.1 \%)$ \\
\hline DAS28 $\leq 3.2$ & $1 / 24(4.2 \%)$ & $0 / 28(0 \%)$ & $1 / 20(5.0 \%)$ & 2/34 (5.9\%) & $0 / 18(0 \%)$ & $2 / 28(7.1 \%)$ \\
\hline
\end{tabular}

aPrimary efficacy outcome. American College of Rheumatology (ACR) results are presented as the cumulative number of patients reaching each ACR level. Population sizes could vary with respect to an efficacy endpoint due to the fact that, for some patients, all efficacy data under treatment were missing (no data imputation was possible in this case). ACR20/50/70, American College of Rheumatology 20\%/50\%/70\% improvement criteria; ACRn, index of improvement in rheumatoid arthritis; anti-TNF $\alpha$, anti-tumour necrosis factor-alpha; CRP, C-reactive protein; DAS28, disease activity score using 28 joint counts; $\triangle \mathrm{DAS} 28$, the change in disease activity score using 28 joint counts from baseline; ITT, intention-totreat; LOCF, last observation carried forward; MTX, methotrexate; OC, observed case; PP, per protocol population; SD, standard deviation.

hence, the dose at time of first response was also analysed. Results reveal that approximately $65 \%$ and $73 \%$ of those patients achieving ACR20 or ACR50 scores, respectively, did so at a dosage of not more than $6 \mathrm{mg} / \mathrm{kg}$ per day. Moreover, this dosage corresponded to the highest response rate $(5 / 15$, 33.3\%) for the ACR50 threshold. For those patients randomly assigned to the $3 \mathrm{mg} / \mathrm{kg}$ per day dosing group, 12/22 (55\%) received dose augmentation at weeks 4 or 8 due to insufficient response. Of these, $7 / 12$ (58\%) patients experienced an improved response within the initial 12-week phase whereas $5 / 12(42 \%)$ patients were nonresponders, having failed to reach the ACR20 threshold.

\section{Discussion}

Although the incidence of AEs was high in the study population as a whole (95\%), the majority of these were mild or moderate in severity, transitory in nature and resolved spontaneously or upon temporary treatment interruption. Moreover, because this was the first study of masitinib as treatment in a nononcologic pathology, the increased incidence of dermatological events typically associated with this therapeutic class [20] was understandably treated with great caution by patients and investigators alike. This may in part explain the relatively high dropout rate of patients. Of those who withdrew from the study because of AEs prior to week 12 


\begin{tabular}{|c|c|c|c|c|c|c|c|}
\hline Parameter & W12 & W24 & W36 & W48 & W60 & W72 & W84 \\
\hline ACR, number (percentage) of patients & $\mathrm{n}=27$ & $\mathrm{n}=7$ & $\mathrm{n}=9$ & $\mathrm{n}=8$ & $\mathrm{n}=8$ & $\mathrm{n}=9$ & $\mathrm{n}=8$ \\
\hline $\mathrm{ACR} 20^{\mathrm{b}}$ & $15(56 \%)$ & $6(86 \%)$ & $7(78 \%)$ & $5(63 \%)$ & $6(75 \%)$ & $6(67 \%)$ & $7(88 \%)$ \\
\hline ACR50b & $9(33 \%)$ & $2(27 \%)$ & $4(44 \%)$ & $3(38 \%)$ & $6(75 \%)$ & $3(33 \%)$ & $5(63 \%)$ \\
\hline ACR70 & $3(11 \%)$ & $1(14 \%)$ & $2(22 \%)$ & $1(13 \%)$ & $3(38 \%)$ & $2(22 \%)$ & $2(25 \%)$ \\
\hline ACR90 & $0(0 \%)$ & $0(0 \%)$ & $1(11 \%)$ & $0(0 \%)$ & $2(25 \%)$ & $1(11 \%)$ & $1(13 \%)$ \\
\hline ACRn & $\mathrm{n}=27$ & $\mathrm{n}=7$ & $\mathrm{n}=9$ & $\mathrm{n}=8$ & $\mathrm{n}=8$ & $\mathrm{n}=9$ & $\mathrm{n}=8$ \\
\hline Mean \pm SD & $31.6 \pm 33.5$ & $36.0 \pm 29.0$ & $45.9 \pm 32.3$ & $30.9 \pm 36.7$ & $58.3 \pm 31.4$ & $35.6 \pm 41.3$ & $50.9 \pm 38.0$ \\
\hline Median & 42.9 & 40.7 & 45.5 & 40.0 & 64.9 & 39.7 & 55.0 \\
\hline Range & $-40.0-87.5$ & $-16.7-73.0$ & $-3.8-93.3$ & $-20.0-70.9$ & $10.0-93.3$ & $-27.8-97.4$ & $-17.6-98.8$ \\
\hline CRP, number (percentage) of patients & $\mathrm{n}=28$ & $\mathrm{n}=7$ & $\mathrm{n}=12$ & $\mathrm{n}=9$ & $\mathrm{n}=7$ & $n=9$ & $\mathrm{n}=8$ \\
\hline Improvement $>50 \%$ & $14(50 \%)$ & $5(71 \%)$ & $9(75 \%)$ & $6(67 \%)$ & $3(43 \%)$ & $6(68 \%)$ & $5(63 \%)$ \\
\hline $25 \%<$ improvement $\leq 50 \%$ & $3(11 \%)$ & $0(0 \%)$ & $1(8 \%)$ & $0(0 \%)$ & $3(43 \%)$ & $1(11 \%)$ & $1(13 \%)$ \\
\hline $0 \%<$ improvement $\leq 25 \%$ & $5(18 \%)$ & $1(14 \%)$ & $1(8 \%)$ & $1(11 \%)$ & $1(14 \%)$ & $1(11 \%)$ & $1(13 \%)$ \\
\hline Stable & $3(11 \%)$ & $1(14 \%)$ & $1(8 \%)$ & $0(0 \%)$ & $0(0 \%)$ & $0(0 \%)$ & $0(0 \%)$ \\
\hline Deterioration & $3(11 \%)$ & $0(0 \%)$ & $0(0 \%)$ & $2(22 \%)$ & $0(0 \%)$ & $1(11 \%)$ & $1(13 \%)$ \\
\hline DAS28 & $n=24$ & $\mathrm{n}=4$ & $\mathrm{n}=5$ & $\mathrm{n}=6$ & $\mathrm{n}=7$ & $\mathrm{n}=7$ & $\mathrm{n}=4$ \\
\hline Mean \pm SD & $4.6 \pm 1.3$ & $5.2 \pm 1.7$ & $4.4 \pm 1.9$ & $4.7 \pm 2.1$ & $3.3 \pm 1.5$ & $3.5 \pm 1.5$ & $3.1 \pm 1.6$ \\
\hline Median & 4.4 & 4.9 & 4.1 & 4.4 & 2.6 & 3.0 & 2.5 \\
\hline Range & $0.5-7.0$ & $3.6-7.5$ & $2.3-7.5$ & $2.7-8.7$ & $1.7-5.3$ & $1.6-6.1$ & $1.9-5.5$ \\
\hline $\begin{array}{l}\text { DAS28 }<2.6 \text {, number (percentage) of } \\
\text { patients }\end{array}$ & $1(4 \%)$ & $0(0 \%)$ & $1(20 \%)$ & $0(0 \%)$ & $4(57 \%)$ & $1(14 \%)$ & $2(50 \%)$ \\
\hline $\begin{array}{l}\text { DAS28 } \leq 3.2, \text { number (percentage) of } \\
\text { patients }\end{array}$ & $1(4 \%)$ & $0(0 \%)$ & $1(20 \%)$ & $2(33 \%)$ & $4(57 \%)$ & $4(57 \%)$ & $3(75 \%)$ \\
\hline
\end{tabular}

aResults from extension phase are preliminary. bPrimary efficacy outcome. American College of Rheumatology (ACR) results are presented as the cumulative number of patients reaching each ACR level. ACR20/50/70/90, American College of Rheumatology 20\%/50\%/70\%/90\% improvement criteria; ACRn, index of improvement in rheumatoid arthritis; DAS28, disease activity score using 28 joint counts; CRP, C-reactive protein; SD, standard deviation; W, week.

$(n=13), 9 / 13(69 \%)$ patients had experienced AEs of a mild or moderate intensity, which could feasibly have been managed without permanent interruption of treatment. In general, AEs occurred early during the course of treatment, which is consistent with the known safety profile of TK inhibitors [21]. This trend is clearly evident when comparing safety data from the initial and extension phases, the implication being that, although masitinib is not completely free from side effects, the majority of these are over following 12 weeks of treatment, with good tolerance experienced thereafter during any longterm treatment regimen. During the initial 12 weeks, the most common AEs were rashes, oedema, nausea and diarrhoea. Cutaneous rash may potentially be linked to the action of masitinib on MCs, inducing MC apoptosis with a subsequent release of various mediators (for example, histamine, prostaglandins or cytokines) that are responsible for rash. This apoptosis seems to happen only once. The time necessary for the released mediators to reach the reaction site and accumulate to a certain concentration in the skin might explain why such events typically manifest themselves between the second and third weeks of treatment. Diarrhoea may also be linked to the pharmacological activity of masitinib on MCs in the intestine or through direct action on Cajals cells of the intestine, which also express the c-KIT receptor. Oedema, mainly palpebral and face oedema, is thought to be linked to the activity of masitinib on PDGFR, a TK receptor involved in the vasculatory pressure of tissues, especially in the periorbital region sensible to low pressure. 
Table 5

Time to first response (days) in intention-to-treat population, according to initial masitinib dosage

\begin{tabular}{lccc}
\hline Parameter & $\begin{array}{c}3 \mathrm{mg} / \mathrm{kg} \text { per day } \\
(\mathrm{n}=22)\end{array}$ & $\begin{array}{c}6 \mathrm{mg} / \mathrm{kg} \text { per day } \\
(\mathrm{n}=18)\end{array}$ & $\begin{array}{c}\text { Total population } \\
(\mathrm{n}=40)\end{array}$ \\
\hline ACR20 & & & $P$ value \\
Patients & $12 / 22(55.0 \%)$ & $11 / 18(61.0 \%)$ & $23 / 40(57.5 \%)$ \\
Mean \pm SD & $51.9 \pm 24.5$ & $40.3 \pm 19.0$ & $46.3 \pm 22.4$ \\
Median & 56.0 & 29.0 & 35.0 \\
Range & $28.0-105.0$ & $28.0-86.0$ & $28.0-105.0$ \\
ACR50 & & $8 / 18(44.0 \%)$ & $15 / 40(37.5 \%)$ \\
Patients & $7 / 22(32.0 \%)$ & $86.8 \pm 61.1$ & $89.1 \pm 58.2$ \\
Mean \pm SD & $91.9 \pm 59.5$ & 72.5 & 84.0 \\
Median & 84.0 & $28.0-203.0$ & $28.0-217.0$ \\
Range & $28.0-217.0$ & 0.771 \\
\hline
\end{tabular}

ACR20, American College of Rheumatology 20\% improvement criteria; ACR50, American College of Rheumatology 50\% improvement criteria; $\mathrm{SD}$, standard deviation.

Overall, the safety profile of masitinib for long-term treatment would appear favourable, especially when considering concerns of cardiotoxicity and genotoxicity. For example, imatinib mesylate (Gleevec, STI571; Novartis, Basel, Switzerland) is cardiotoxic due to its strong inhibition of the Abelson kinase (ABL) $[22,23]$, making its long-term use questionable for treatment of active RA. Masitinib, in contrast, is a weak inhibitor of BCR-ABL (and is also either an inactive or a weak inhibitor of other known cardiotoxic kinases such as Src and vascular endothelial growth factor receptor [VEGFR]), implying that masitinib may exhibit a better safety profile than other TK inhibitors, particularly on cardiac functions (P. Dubreuil and colleagues, manuscript submitted). Preclinical studies have also shown that masitinib is not genotoxic.

The performance of masitinib, with respect to the primary endpoint ACR scores, compares favourably to other biological DMARDs, including rituximab, abatacept and adalimumab [24-27]. Moreover, due to a lack of dosage increase in the event of insufficient response without toxicity (a protocol deviation), some patients may not have benefited from an optimal masitinib dose with a consequent reduction in efficacy results. Observed clinical improvement was supported by laboratory evidence of reduced inflammation in the form of a significant and sustainable decrease in CRP level for approximately half the study population. This result is important since, in the absence of a control group, it serves as proof that the observed improvements are attributable to the treatment. The results from other secondary endpoints (ACRn and DAS28) provide additional evidence of efficacy, with consistent patterns to the primary endpoint regarding sustainability and independence from previous treatment failure.
Dose-response analyses tentatively indicate that a dose level of $6 \mathrm{mg} / \mathrm{kg}$ per day is the most potent, although inequality of baseline clinical parameters between dose groups may be a confounding influence. Hence, no definite conclusion on the optimal initial dosing level can be reached. In regard to tolerability, the majority of severe AEs were associated with doses of at least $7.5 \mathrm{mg} / \mathrm{kg}$ per day. Thus, utilisation of not more than $6 \mathrm{mg} / \mathrm{kg}$ per day would likely reduce the occurrence of severe $\mathrm{AEs}$, in particular those associated with oedema.

\section{Conclusions}

Within the limitations of an uncontrolled phase $2 a$ trial, this study has indicated that masitinib is a generally well-tolerated (especially after the initial 12 weeks) and effective treatment for DMARD-refractory active RA. Given the selective antimastocyte mechanism of action of masitinib, the results of this study help to further establish the critical role of MCs in the pathogenesis of active RA. More specifically, this study supports the viability of exploiting the SCF/c-KIT pathway as a therapeutic target. There is sufficient compelling evidence to proceed to phase $2 b / 3$ randomised clinical trials to confirm and further characterise these findings.

\section{Competing interests}

AM, LG, PD and $\mathrm{OH}$ are employees and shareholders of the study sponsor, AB Science. PGi and CDM are employees of the study sponsor. $A B$ Science is the proprietary holder of masitinib (AB1010). The other authors declare that they have no competing interests.

\section{Authors' contributions}

JT was the main contributor to recruitment and treatment of the patients, contributing also to data analysis and interpretation and to preparation of the manuscript. XM was a co-coordinat- 
ing clinical investigator who contributed to the study's conception and design, patient recruitment and treatment, data analysis and interpretation, and manuscript preparation. PB, $\mathrm{R}-\mathrm{MF}, \mathrm{PGa}$ and XLL were clinical investigators who contributed to the recruitment and treatment of the patients. PGi, AM and $\mathrm{OH}$ contributed to the study's conception and design, data analysis and interpretation, and manuscript preparation. LG contributed to the study's conception and design and to analysis and interpretation of the data. CDM, a medical writer at $A B$ Science, contributed to data analysis and interpretation and was the main contributor in the preparation of the manuscript. PD contributed to the conception and design of the study and contributed analytical tools. JS was a co-coordinating clinical investigator who contributed to the study's conception and design, patient recruitment and treatment, and data analysis and interpretation. All authors critically reviewed the manuscript and gave final approval of the version to be published.

\section{Acknowledgements}

This study was financially supported by AB Science, which was involved in the study design, data analysis and interpretation, manuscript preparation and the decision to submit the manuscript. The authors wish to thank the Biometry Department of AB Science for performing statistical analyses.

\section{References}

1. Kremer JM: Rational use of new and existing disease-modifying agents in rheumatoid arthritis. Ann Intern Med 2001, 134:695-706.

2. Emery P, Breedveld FC, Hall S, Durez P, Chang DJ, Robertson D, Singh A, Pedersen RD, Koenig AS, Freundlich B: Comparison of methotrexate monotherapy with a combination of methotrexate and etanercept in active, early, moderate to severe rheumatoid arthritis (COMET): a randomised, double-blind, parallel treatment trial. Lancet 2008, 372:375-382.

3. Heijden JW van der, Dijkmans BAC, Scheper RJ, Jansen G: Drug Insight: resistance to methotrexate and other disease-modifying antirheumatic drugs - from bench to bedside. Nat Clin Pract Rheumatol 2007, 3:26-34.

4. Maetzel A, Wong A, Strand V, Tugwell P, Wells G, Bombardier C: Meta-analysis of treatment termination rates among rheumatoid arthritis patients receiving disease-modifying anti-rheumatic drugs. Rheumatology (Oxford) 2000, 39:975-981.

5. Flendrie M, Creemers MC, Welsing PM, den Broeder AA, van Riel $\mathrm{PL}$ : Survival during treatment with tumour necrosis factor blocking agents in rheumatoid arthritis. Ann Rheum Dis 2003, 62(Suppl 2):ii30-ii33.

6. Lee DM, Friend DS, Gurish MF, Benoist C, Mathis D, Brenner MB: Mast cells: a cellular link between autoantibodies and inflammatory arthritis. Science 2002, 297:1689-1692.

7. Nigrovic PA, Binstadt BA, Monach PA, Johnsen A, Gurish M, Iwakura $Y$, Benoist $C$, Mathis D, Lee DM: Mast cells contribute to initiation of autoantibody-mediated arthritis via IL-1. Proc Natl Acad Sci USA 2007, 104:2325-2330.

8. Paniagua RT, Sharpe O, Ho PP, Chan SM, Chang A, Higgins JP, Tomooka BH, Thomas FM, Song JJ, Goodman SB, Lee DM, Genovese MC, Utz PJ, Steinman L, Robinson WH: Selective tyrosine kinase inhibition by imatinib mesylate for the treatment of autoimmune arthritis. J Clin Invest 2006, 116:2633-2642.

9. Nigrovic PA, Lee DM: Synovial mast cells: role in acute and chronic arthritis. Immunol Rev 2007, 217:19-37.

10. Eklund KK: Mast cells in the pathogenesis of rheumatic diseases and as potential targets for anti-rheumatic therapy. Immunol Rev 2007, 217:38-52.

11. Juurikivi A, Sandler C, Lindstedt KA, Kovanen PT, Juutilainen $T$, Leskinen MJ, Mäki T, Eklund KK: Inhibition of c-kit tyrosine kinase by imatinib mesylate induces apoptosis in mast cells in rheumatoid synovia: a potential approach to the treatment of arthritis. Ann Rheum Dis 2005, 64:1126-1131.

12. Kobayashi $\mathrm{Y}$, Okunishi $\mathrm{H}$ : Mast cells as a target of rheumatoid arthritis treatment. Jpn J Pharmaco/ 2002, 90:7-11.

13. Ceponis A, Konttinen YT, Takagi M, Xu JW, Sorsa T, MatucciCerinic M, Santavirta S, Bankl HC, Valent P: Expression of stem cell factor (SCF) and SCF receptor (c-kit) in synovial membrane in arthritis: correlation with synovial mast cell hyperplasia and inflammation. J Rheumatol 1998, 25:2304-2314.

14. Reber L, DaSilva CA, Frossard N: Stem cell factor and its receptor c-Kit as targets for inflammatory diseases. Eur J Pharmacol 2006, 533:327-340.

15. Arnett FC, Edworthy SM, Bloch DA, McShane DJ, Fries JF, Cooper NS, Healey LA, Kaplan SR, Liang MH, Luthra HS, Medsger TA Jr, Mitchell DM, Neustadt DH, Pinals RS, Schaller JG, Sharp JT, Wilder RL, Hunder GG: The American Rheumatism Association 1987 revised criteria for the classification of rheumatoid arthritis. Arthritis Rheum 1988, 31:315-324.

16. Hochberg MC, Chang RW, Dwosh I, Lindsey S, Pincus T, Wolfe F: The American College of Rheumatology 1991 revised criteria for the classification of global functional status in rheumatoid arthritis. Arthritis Rheum 1992, 35:498-502.

17. Felson DT, Anderson JJ, Boers M, Bombardier C, Furst D, Goldsmith C, Katz LM, Lightfoot R Jr, Paulus H, Strand V, Tugwell P, Weinblatt M, Williams HJ, Wolfe F, Kieszak S: American College of Rheumatology: preliminary definition of improvement in rheumatoid arthritis. Arthritis Rheum 1995, 38:727-735.

18. Prevoo MLL, van't Hof MA, Kuper HH, van Leeuwen MA, Putte LBA van de, van Riel PLCM: Modified disease activity scores that include twenty-eight-joint counts. Development and validation in a prospective longitudinal study of patients with rheumatoid arthritis. Arthritis Rheum 1995, 38:44-48.

19. Siegel JN, Zhen BG: Use of the American College of Rheumatology N (ACR-N) Index of Improvement in Rheumatoid Arthritis: argument in favor. Arthritis Rheum 2005, 52:1637-1641.

20. Flendrie M, Vissers WHPM, Creemers MCW, de Jong EMGJ, Kerkhof PCM van de, van Riel PLCM: Dermatological conditions during TNF- $\alpha$-blocking therapy in patients with rheumatoid arthritis: a prospective study. Arthritis Res Ther 2005, 7:R666-R676.

21. Van Glabbeke M, Verweij J, Casali PG, Simes J, Le Cesne A, Reichardt $P$, Issels R, Judson IR, van Oosterom AT, Blay JY: Predicting toxicities for patients with advanced gastrointestinal stromal tumours treated with imatinib: a study of the European Organisation for Research and Treatment of Cancer, the Italian Sarcoma Group, and the Australasian Gastro-Intestinal Trials Group (EORTC-ISG-AGITG). Eur J Cancer 2006, 42:2277-2285.

22. Kerkela R, Grazette L, Yacobi R, lliescu C, Patten R, Beahm C, Walters B, Shevtsov S, Pesant S, Clubb FJ, Rosenzweig A, Salomon RN, Van Etten RA, Alroy J, Durand JB, Force T: Cardiotoxicity of the cancer therapeutic agent imatinib mesylate. Nat Med 2006, 12:908-916.

23. Fernandez A, Sanguino A, Peng Z, Ozturk E, Chen J, Crespo A, Wulf S, Shavrin A, Qin C, Ma J, Trent J, Lin Y, Han HD, Mangala LS, Bankson JA, Gelovani J, Samarel A, Bornmann W, Sood AK, Lopez-Berestein G: An anticancer C-Kit kinase inhibitor is reengineered to make it more active and less cardiotoxic. J Clin Invest 2007, 117:4044-4054.

24. Edwards JC, Szczepanski L, Szechinski J, Filipowicz-Sosnowska A, Emery P, Close DR, Stevens RM, Shaw T: Efficacy of B-celltargeted therapy with rituximab in patients with rheumatoid arthritis. N Engl J Med 2004, 350:2572-2581.

25. Kremer JM, Dougados M, Emery P, Durez P, Sibilia J, Shergy W, Steinfeld S, Tindall E, Becker JC, Li T, Nuamah IF, Aranda R, Moreland LW: Treatment of rheumatoid arthritis with the selective costimulation modulator abatacept: twelve-month results of a phase $2 \mathrm{~b}$, double-blind, randomized, placebo-controlled trial. Arthritis Rheum 2005, 52:2263-2271.

26. Putte LBA van de, Rau R, Breedveld FC, Kalden JR, Malaise MA Schattenkirchner M, Emery P, Burmester GR, Zeidler H, Moutsopoulos HM, Beck K, Kupper $\mathrm{H}$ : Efficacy and safety of the fully human anti-TNF- $\alpha$ monoclonal antibody, adalimumab (D2E7), in DMARD-refractory patients with rheumatoid arthritis: a 12week, phase II study. Ann Rheum Dis 2003, 62:1168-1177. 
Arthritis Research \& Therapy Vol 11 No 3 Tebib et al.

27. Putte LBA van de, Atkins $C$, Malaise M, Sany J, Russell AS, van Riel PLCM, Settas L, Bijlsma JW, Todesco S, Dougados M, Nash P, Emery P, Walter N, Kaul M, Fischkoff S, Kupper H: Efficacy and safety of adalimumab as monotherapy in patients with rheumatoid arthritis for whom previous disease modifying antirheumatic drug treatment has failed. Ann Rheum Dis 2004, 63:508-516. 